DOI: https://doi.org/10.15407/kvt199.01.039

UDC 519.688

MISHCHENKO M.D. ${ }^{1}$, Student e-mail: mishenkomihailo@gmail.com GUBAREV V.F. ${ }^{2}$, DSc. (Engineering), Corresponding Member of NAS of Ukraine, Head of the Dynamic Systems Control Department e-mail: v.f.gubarev@gmail.com ${ }^{1}$ National Technical University of Ukraine "Igor Sikorsky Kyiv Polytechnic Institute" 37, Peremohy av., 03056, Kyiv, Ukraine ${ }^{2}$ Space Research Institute of the National Academy of Sciences of Ukraine and the State Space Agency of Ukraine 40, Acad. Glushkova, 03187, Kyiv, Ukraine

\title{
METHODS OF MODEL PREDICTIVE CONTROL FOR DISCRETE MULTI-VARIABLE SYSTEMS WITH INPUT
}

Introduction. There are a lot of systems which can be conveniently modelled as a discrete linear multi-input multi-variable system. When a control problem for such systems arises, it is usually done with methods derived from the control theory. But these methods have several known drawback. For example, for non-deterministic systems, they are based on assumption about certain convenient statistical properties of noises.

The purpose of the paper is to develop synthesis algorithms based on ideas and approaches of the Model Predictive Control (MPC).

Methods. In contrast to the common approach, in this work we aim to synthesize the best control sequence in terms of some criterion. We use results derived from the KuhnTucker theorem for control synthesis.

Results. A new class of methods capable of leading linear system's state to zero (or, in case of noisy environment, to its neighbourhood) and stabilization of cognitive map's functioning was developed. These new methods are capable of controlling not only stable systems, but also unstable and semi-stable ones, even in presence of random perturbations and with constrained control resource. These methods differ in efficiency of control resource utilization and required computational resources. More efficient methods require more computations. That's why it is necessary to choose an appropriate method in each particular case.

Conclusions. The developed methods can be used to control both technical and any other kinds of systems represented either as controllable linear multi-variable systems with input or as controllable cognitive maps.

Keywords: variational method, cognitive map, control synthesis, discrete controllable system, moving horizon, linear system, MPC. 


\section{INTRODUCTION}

Growing profit and activity in model predictive control (MPC) in recent years are first of all connected with an attempt to use the powerful computer technology to improve the control of multi-variable complex processes containing uncertainties and constraints. If five years ago MPC occupied modest place among popular control methods then now according to report presented by Allgöwer on the International Scientific Conference "Dynamical Systems: Stability, Control, Optimization", Minsk, Belarus, September 2018, these methods enter into leading position. It is no wonder that there are many publications devoted to MPC where one can find not only theoretical aspects of this problems [1-6] but also successful applications especially in the process industries [6, 7].

Original methods of MPC problem solving for discrete linear multi-input multi-variable (MIMV) system are proposed and theoretically substantiated in the paper. The approach is based on a Cauchy formula which represents through the use of the controllability matrix the solution for discrete linear multivariable system with input. Such approach reduces optimal control problems to squared programming ones, which in turn allows us to use necessary conditions for optimality in analytical form to write its solution. Due to this it is enough simply to take into account constraints for control and to apply different stabilizing control strategies under bounded uncertainty.

The paper is organized as follows. Problem Definition section contains the problem setting and MPC Approach to MINV Systems' Control section develops its formulation using for this MPC approach on the base of Cauchy formula for discrete systems. Some attainability conditions are formulated in the form of convergence theorems. Main results are contained in Solving Methods section where variational and optimal aim solving methods are stated. Feedback Stabilization section different control strategies on top of the developed solving methods are proposed. Lastly, there is Conclusions section which summarizes particular qualities of the findings related to the application of obtained results

\section{PROBLEM DEFINITION}

Let there be a controlled discrete dynamic multi-input multi-variable system. It can be either deterministic or stochastic. The system is defined as

$$
x_{k+1}=A x_{k}+B u_{k}+d_{k},
$$

where $x_{k}$ and $x_{k+1}$ are consecutive states of the system, $u_{k}$ is a control, applied to it at $k$-th point of time, $d_{k}$ is the random perturbation at the moment $k, A$ and $B$ are system matrices. We assume that $A$ and $B$ have full ranks. States are $n$-dimensional vectors, and controls are $r$-dimensional. In deterministic variant perturbation $d_{k}$ is always equal to 0 .

There is a known state $x_{k}$ at the moment $k$. Our task is to lead the system's state into a predefined point $x^{*}$ (or, in stochastic case, into its neighbourhood) in finite time and keep it there for indefinite amount of time with synthesized controls. 
In practice, control resource is usually bounded. So, we define its constraints as

$$
\left|u_{k i}\right| \leq u_{\max i}, k \in \mathbf{Z}, i \in \overline{1, r} \text {, }
$$

where $u_{\max }$ is a vector of some positive values.

We also assume that values of $d$ are constrained in a way, that they do not exceed the control resource, described in (2).

\section{MPC APPROACH TO MINV SYSTEMS' CONTROL}

Consider MPC approach to MINV control problem as given in (1). Its main aim is to produce a linear equation which allows to calculate on each step a new control using previous controls and system's states (or their estimations), so that the combination of the original system and such controller were stable in different senses and converge asymptotically to the needed point.

In contradiction with this, our approach is to find the best (in terms of some criterions) sequence of controls among the set of all possible such sequences, satisfying constraints (2).

The common point in the discussed methods is that the controls are calculated for predefined number of steps $s$ called finite horizon at once. Thus, the defining equation of the system (1) in the deterministic case $\left(d_{k}=0\right)$ is transformed into

$$
\begin{gathered}
\Omega_{s} u(k, s)=x_{k+s}-A^{s} x_{k}, \\
u(k, s)=\left(\begin{array}{c}
u_{k} \\
\vdots \\
u_{k+s-1}
\end{array}\right), \\
\Omega_{s}=\left(\begin{array}{lllll}
A^{s-1} B & A^{s-2} B & \ldots & A B & B
\end{array}\right) .
\end{gathered}
$$

In this case our goal is to synthesize such $u(k, s)$, that provides $x_{k+s}=x^{*}$ and constraints (2).

In the stochastic case instead of (3) we get

$$
\Omega_{s} u(k, s)=x_{k+s}-A^{s} x_{k}-\sum_{i=k}^{k+s-1} A^{k+s-1-i} d_{i} .
$$

There are two main approaches in control of systems with random perturbations: robust and probabilistic. In next two subsections we will show from this two standpoints, that in the stochastic case we also should use the control, which satisfies (3), where $x_{k+s}=x^{*}$.

Robust control. According to (4), if there are no constraints on values of $d$, the system is assumed to be uncontrollable, because for every predetermined control $u(k, s)$ the set of possible future states at the $k+s$ point of time is 
unbounded. If at the stage of controller development there are known constraints on perturbations in form

$$
\left|d_{k i}\right| \leq d_{\max i}, k \in \mathbf{Z}, i \in \overline{1, n}
$$

where vector $d_{\max }$ consists of given positive numbers, then the value of the future state $x_{k+s}$ at the point of time $k+s$ with MPC without feedback is constrained by a polyhedron with point of symmetry $\Omega_{s} u(k, s)+A^{s} x_{k}$, according to formula

$$
x_{k+s}=\Omega_{s} u(k, s)+A^{s} x_{k}+\sum_{i=k}^{k+s-1} A^{k+s-1-i} d_{i}
$$

using measured current state $x_{k}$ or its estimation.

Thereby, it is natural to synthesize such a control, that the point of symmetry of this polyhedron coincides with the aim $x^{*}$. Controls with this property are described with the same equation (3). This statement of the problem can be called robust with respect to external perturbations. Then there is a bounded neighbourhood of the aimed state, where the system is guaranteed to reach with the appropriately synthesized feedback controls if the perturbations do not violate their constraints (5).

Probabilistic control. If it is known about the perturbations, that $\mathrm{E}[d]=0$ and that they are mutually independant, then we can express $\mathrm{E}\left[x_{k+s}\right]$ as in

$$
\mathrm{E}\left[x_{k+s}\right]=\mathrm{E}\left[\Omega_{s} u(k, s)+A^{s} x_{k}+\sum_{i=k}^{k+s-1} A^{k+s-1-i} d_{i}\right]=\Omega_{s} u(k, s)+A^{s} x_{k} .
$$

Thus, we get equation

$$
\Omega_{s} u(k, s)=\mathrm{E}\left[x_{k+s}\right]-A^{s} x_{k} .
$$

With this statement of the problem it is natural to synthesize such a control, so that $\mathrm{E}\left[x_{k+s}\right]=x^{*}$. This again reduces the control synthesis problem to solving the equation (3), where we substitute $x_{k+s}$ with $x^{*}$ with linear constraints (2).

Control update. It is obvious, that if we can measure each current state of the system, it is wise to recalculate future controls taking into account measured system state which may be different due to acting unknown perturbation. It gives us some kind of feedback MPC, that allows us to take into account previous disturbances. In practice, this allows us to realize effective control in noisy environment in comparison with unchanged synthesized control sequence. 


\section{ATTAINABILITY CONDITION}

If for the particular prediction horizon $s$ the aim $x^{*}$ is not reachable from the current state $x_{k}$, it is desirable at least to have some kind of rule, which helps us to handpick some another reachable aim, so that sequence of such intermediate aims will either end up in a state, from where the original aim is reachable, or at least will converge to the original aim. It is obvious, that if the aim $x^{*}$ is reachable in $s_{2}$ steps, where $s_{2}=k s, k \in \mathbf{N}, k \geq 2$, than such sequence exists, but in general case it is not obvious how to construct it without simply incrementing $s$ until we find the desired control sequence. But in case when $x^{*}=0$ (stabilization problem) we can formulate such a rule, which satisfies conditions of theorem 1, 2, 3 or 4 .

In the following theorems we assume, that $\|A\| \geq 1$, because otherwise the system will converge to 0 even without any controls.

Theorem 1 ( $1^{\text {st }}$ convergence condition). Let $\widetilde{x}_{0}=x_{k}$ and $\widetilde{x}_{i+1}$ be the next intermediate aim chosen from state $\tilde{x}_{i}$. If $\left\|\widetilde{x}_{i+1}\right\| \leq\left\|\widetilde{x}_{i}\right\|-\delta, \delta>0$, then the system's state will reach $\delta$-neighbourhood of 0 in finite number of iterations. If this inequality remains right until 0 becomes reachable in steps, then the system will reach such state in finite number of iterations.

Proof.

$$
\left\|\widetilde{x}_{i}\right\| \leq\left\|\widetilde{x}_{0}\right\|-i \delta
$$

As we can see from (6), there is such number $i$, so that $\left\|\widetilde{x}_{0}\right\|-i \delta \leq \delta$.

Theorem 2 (Consequence of the theorem 1). Let $\tilde{x}_{0}=x_{k}$ and $\tilde{x}_{i+1}$ be the next intermediate aim chosen from state $\tilde{x}_{i}$. If $\left\|A^{s} \widetilde{x}_{i}\right\|-\left\|\widetilde{x}_{i+1}\right\| \geq\left(\left\|A^{s}\right\|-1\right)\left\|\widetilde{x}_{i}\right\|+\delta, \delta>0$, then the system's state will reach $\delta$-neighbourhood of 0 in finite number of iterations. If this inequality remains right until 0 becomes reachable in steps, then the system will reach such state in finite number of iterations.

Proof.

$$
\left\|\widetilde{x}_{i+1}\right\| \leq\left\|A^{s} \widetilde{x}_{i}\right\|-\left(\left\|A^{s}\right\|-1\right)\left\|\widetilde{x}_{i}\right\|-\delta \leq\left\|\widetilde{x}_{i}\right\|-\delta
$$

From (7) follows, that the requirements of the theorem 1 is fulfilled.

Theorem 3 ( $2^{\text {nd }}$ convergence condition). Let $\tilde{x}_{0}=x_{k}$ and $\tilde{x}_{i+1}$ be next intermediate aim chosen from state $\tilde{x}_{i}$. If $\left\|A^{s}\right\|\left\|\widetilde{x}_{i}\right\|-\left\|\widetilde{x}_{i+1}\right\| \geq\left(\left\|A^{s}\right\|-1\right)\left\|\widetilde{x}_{0}\right\|+\delta$, $\delta>0$ for every ifor which 0 is not reachable from $\tilde{x}_{i}$ in steps, then the system will reach such state in finite number of iterations. 
Proof.

$$
\begin{aligned}
& \left\|\tilde{x}_{i+1}\right\| \leq\left\|A^{s}\right\|\left\|\widetilde{x}_{i}\right\|-\left(\left\|A^{s}\right\|-1\right)\left\|\widetilde{x}_{0}\right\|-\delta=\left\|A^{s}\right\|\left(\left\|\widetilde{x}_{i}\right\|-\left\|\widetilde{x}_{0}\right\|\right)+\left\|\widetilde{x}_{0}\right\|-\delta \leq \\
& \left\|A^{s}\right\|\left(\left\|A^{s}\right\|\left\|\widetilde{x}_{i-1}\right\|-\left\|A^{s}\right\|\left\|\widetilde{x}_{0}\right\|-\delta\right)+\left\|\widetilde{x}_{0}\right\|-\delta \leq \\
& \left\|A^{s}\right\|^{2}\left(\left\|\widetilde{x}_{i-1}\right\|-\left\|\widetilde{x}_{0}\right\|\right)+\left\|\widetilde{x}_{0}\right\|-\left(1+\left\|A^{s}\right\|\right) \delta \leq \ldots \\
& \ldots \leq\left\|A^{s}\right\|^{i+1}\left(\left\|\widetilde{x}_{0}\right\|-\left\|\widetilde{x}_{0}\right\|\right)+\left\|\widetilde{x}_{0}\right\|-\delta \sum_{k=0}^{i}\left\|A^{s}\right\|^{k}=\left\|\widetilde{x}_{0}\right\|-\delta \sum_{k=0}^{i}\left\|A^{s}\right\|^{k}
\end{aligned}
$$

As we can see from (8), this process can continue only finite number of iterations.

Theorem 4 (Consequence of the theorem 3). Let $\tilde{x}_{0}=x_{k}$ and $\tilde{x}_{i+1}$ is next intermediate aim chosen from state $\tilde{x}_{i}$. If $\left\|A^{s} \widetilde{x}_{i}\right\|-\left\|\widetilde{x}_{i+1}\right\| \geq\left(\left\|A^{s}\right\|-1\right)\left\|\widetilde{x}_{0}\right\|+\delta$, $\delta>0$ for every i for which 0 is not reachable from $\tilde{x}_{i}$ in steps, then the system will reach such state in finite number of iterations.

Proof.

$$
\left\|A^{s} \widetilde{x}_{i}\right\|-\left\|\tilde{x}_{i+1}\right\| \leq\left\|A^{s}\right\|\left\|\widetilde{x}_{i}\right\|-\left\|\widetilde{x}_{i+1}\right\|
$$

From (9) follows, that the requirements of the theorem 3 is fulfilled.

\section{SOLVING METHODS}

\section{Variational Method}

The core idea of the variational method is to calculate the optimal control without taking into account any constraints, and only after they will be taken in account for analytical solution obtained.

The control is calculated in following scheme: firstly, we partition $\Omega_{s}$ columnwise into matrices $\Omega_{\mathrm{s}}^{I_{1}}$ and $\Omega_{\mathrm{s}}^{I_{2}}$, so that $\Omega_{\mathrm{s}}^{I_{1}}$ is square and invertible, and $\Omega_{\mathrm{s}}^{I_{2}}$ contains all remaining columns.

We can calculate parts of $u(k, s)\left(u_{I_{1}}(k, s)\right.$ and $\left.u_{I_{2}}(k, s)\right)$ as in

$$
\begin{aligned}
& u_{I_{1}}(k, s)=\left[\Omega_{\mathrm{s}}^{I_{1}}+\Omega_{\mathrm{s}}^{I_{2}}\left(\Omega_{\mathrm{s}}^{I_{2}}\right)^{\mathrm{T}}\left(\Omega_{\mathrm{s}}^{I_{1}}\right)^{-1}\right]^{-1}\left(x^{*}-A^{s} x_{k}\right) \quad \text { and } \\
& u_{I_{2}}(k, s)=\left(\Omega_{\mathrm{s}}^{I_{2}}\right)^{\mathrm{T}}\left(\Omega_{\mathrm{s}}^{I_{1}}\right)^{-1} u_{I_{1}}(k, s) .
\end{aligned}
$$

For detailed proof see [8].

As a result, we get a straightforward formula to calculate a control sequence $u(k, s)$ for every given current state $x_{k}$ and aim $x^{*}$ in form of a linear equation

$$
u(k, s)=K\left(x^{*}-A^{s} x_{k}\right),
$$

where $K$ is built according to the equations (10) and (11). 
As it was already said, the result calculated in this way is not necessarily satisfies constraints (2). But if $x^{*}=0$, then we can use some kind of convergence strategy, as it was described in the Attainability Condition section. In this section we propose two different convergence strategies: linear approach and projection approach.

Linear Approach Strategy. The main idea of the linear approach is to apply control $\tilde{u}(k, s)$, calculated as in

$$
\tilde{u}(k, s)=\left(\min _{i \in 1 \ldots s r} \frac{u_{\max i}}{\left|u_{i}(k, s)\right|}\right) \cdot u(k, s)
$$

if $u(k, s)$ does not satisfy constraints (2).

Theorem 5. If $\left\|\widetilde{x}_{0}\right\|<\frac{1}{\left\|A^{*}\right\|-1} \min _{j \in \overline{1 . . . s r}} \frac{u_{\max j}}{\left\|K_{j}\right\|}$, where $K_{j}$ is the j-th row of $K$, then applying $\tilde{u}(k, s)$ calculated as in (12) to the deterministic variant of the system will produce a sequence of $\widetilde{x}_{i}$, which satisfies the theorem 4.

Proof. If $u(k+i s, s)$ satisfies constraints (2), then 0 can be reached from state $\tilde{x}_{i}$ with $u(k+i s, s)$ control. In other case, we can deduce following.

Let us denote $\alpha_{i}$ as in

$$
\alpha_{i}=\min _{j \in 1 \ldots s r} \frac{u_{\max j}}{\left|u_{j}(k+i s, s)\right|} .
$$

It is obvious, that $0<\alpha_{i}<1$.

$$
\begin{gathered}
\Omega_{s} u(k+i s, s)=0-A^{s} \widetilde{x}_{i}, \\
\Omega_{s} \widetilde{u}(k+i s, s)=\widetilde{x}_{i+1}-A^{s} \widetilde{x}_{i}, \\
\tilde{x}_{i+1}-A^{s} \widetilde{x}_{i}=\Omega_{s}\left(\alpha_{i} u(k+i s, s)\right)=\alpha_{i} \Omega_{s} u(k+i s, s)=-\alpha_{i} A^{s} \widetilde{x}_{i}, \\
\tilde{x}_{i+1}=\left(1-\alpha_{i}\right) A^{s} \widetilde{x}_{i} .
\end{gathered}
$$

Using the Cauchy-Bunyakovsky-Schwarz inequality, we can limit $\alpha_{i}$ as in

$$
\alpha_{i}=\min _{j \in 1 \ldots s r} \frac{u_{\max j}}{\left|K_{j} A^{s} \widetilde{x}_{i}\right|} \geq \min _{j \in 1 \ldots s r} \frac{u_{\max j}}{\left\|K_{j}\right\|} \cdot \frac{1}{\left\|A^{s} \widetilde{x}_{i}\right\|}
$$




$$
\begin{aligned}
& \left\|A^{s} \tilde{x}_{i}\right\|-\left\|\widetilde{x}_{i+1}\right\|=\left\|A^{s} \widetilde{x}_{i}\right\|-\left(1-\alpha_{i}\right)\left\|A^{s} \widetilde{x}_{i}\right\|=\alpha_{i}\left\|A^{s} \widetilde{x}_{i}\right\| \geq \\
& \min _{j \in 1 \ldots s r} \frac{u_{\max j}}{\left\|K_{j}\right\|} \cdot \frac{1}{\left\|A^{s} \widetilde{x}_{i}\right\|}\left\|A^{s} \widetilde{x}_{i}\right\|=\min _{j \in 1 \ldots s r} \frac{u_{\max j}}{\left\|K_{j}\right\|}>\left(\left\|A^{s}\right\|-1\right)\left\|\widetilde{x}_{0}\right\| .
\end{aligned}
$$

Let us define $\delta$ as

$$
\delta=\min _{j \in 1 \ldots s r} \frac{u_{\max j}}{\left\|K_{j}\right\|}-\left(\left\|A^{s}\right\|-1\right)\left\|\widetilde{x}_{0}\right\| .
$$

Thus, we can write inequality

$$
\left\|A^{s} \widetilde{x}_{i}\right\|-\left\|\widetilde{x}_{i+1}\right\| \geq\left(\left\|A^{s}\right\|-1\right)\left\|\widetilde{x}_{0}\right\|+\delta .
$$

$\delta>0$, so the conditions of the theorem 4 are satisfied.

As a byproduct of the variational method of control, we get theorem 6 .

Theorem 6. For the linear MINV system for every $s$ there is an $\varepsilon$ neighbourhood of 0 , from which it is reachable in s iterations with controls satisfying constraints (2). Also, $\varepsilon \geq \min _{i \in 1 \ldots s r} \frac{u_{\max i}}{\left\|K_{i}\right\|}$, where $K_{i}$ is the $i$-th row of $K$.

Proof. Let's try to generate an $s$-step control sequence $u(k, s)$ from some state $x_{k}$ to 0 using the variational method.

$$
u(k, s)=-K A^{s} x_{k}
$$

Using the Cauchy-Bunyakovsky-Schwarz inequality, we get inequality

$$
\left|u_{i}(k, s)\right| \leq\left\|K_{i}\right\| \cdot\left\|x_{k}\right\|, i \in \overline{1 \ldots s r} .
$$

So,

$$
u_{\max i} \geq\left\|K_{i}\right\| \cdot\left\|x_{k}\right\|, i \in \overline{1 \ldots s r}
$$

is sufficient for control (13) to be valid.

From (14) we get

$$
\left\|x_{k}\right\| \leq \min _{i \in 1 \ldots s r} \frac{u_{\max i}}{\left\|K_{i}\right\|}
$$

In the variational method the control synthesis problem was considered as one without any constraints on controls at first. After obtaining a solution in analytic form the set of reachable states is artificially reduced to those, which are reachable by using the controls synthesized with this method.

Projection Approach Strategy. Another approach is to select a projection of 0 onto the set of states reachable from $\tilde{x}_{i}$ in $s$ iterations with controls generated 
with the variational method. In other words, each $\tilde{x}_{i+1}$ is a solution of quadratic programming problem

$$
\begin{aligned}
\min _{x^{\#}} & \left\langle x^{\#}, x^{\#}\right\rangle \\
\text { subject to } & -u_{\max i} \leq K_{i}\left(x^{\#}-A^{s} \widetilde{x}_{i}\right) \leq u_{\max i}, i \in \overline{1 \ldots s r} .
\end{aligned}
$$

It is obvious, that the resulting next intermediate aim $\tilde{x}_{i+1}$ is such that its norm is less or equal to norm of the intermediate aim computed from the same current state $\tilde{x}_{i}$ with linear approach. So, the projection approach strategy also satisfies the theorem 4 .

\section{Optimal Aim Approach}

The optimal aim method was proposed in [8, Sect. 5]. In this method we are repeatedly solving the problem

$$
\begin{array}{r}
\min J(u(k, s))=\frac{1}{2}\left(\left\langle\Omega_{s} u(k, s)+A^{s} x_{k}-x^{*}, \Omega_{s} u(k, s)+A^{s} x_{k}-x^{*}\right\rangle+\right. \\
\alpha\langle u(k, s), u(k, s)\rangle)
\end{array}
$$

with constraints (2), while decreasing values of positive coefficient $\alpha$.

We can describe reachable states' set $X_{\text {reach }}$ as

$$
X_{\text {reach }}=\left\{x: x=\Omega_{s} u+A^{s} x_{k},-u_{\max i} \leq u_{i} \leq u_{\max i}, i \in \overline{1 \ldots s r}\right.
$$

and projection $x^{\#}$ of $x^{*}$ onto it as

$$
x^{\#}=\arg \min _{x \in X_{\text {reach }}}\left\|x-x^{*}\right\| .
$$

Theoretically, we can say, that statements

$$
\begin{array}{ll}
\Omega_{s} u(k, s)+A^{s} x_{k} \rightarrow x_{\alpha \rightarrow 0}^{\#} & \text { and } \\
u(k, s) \underset{\alpha \rightarrow 0}{\rightarrow} \arg \min _{\Omega_{s} u+A^{s} x_{k}=x^{\#}}\langle u, u\rangle &
\end{array}
$$

are true, so this way we can find with certain precision a control, which brings the deterministic variant of system at the point of time $k+s$ as close as possible to $x^{*}$. It is uncertain, if it will produce a sequence of intermediate aims, which converges to the original aim $x^{*}$ in general case.

Luckily, if $x^{*}=0$, then this way we find a control $u(k, s)$, which brings the system's state even closer to 0 (or at least not further), than the linear approach of the variational method, in case we can not reach 0 in $s$ iterations yet. This way we can guaranty, that in this case the sequence of intermediate aims will converge to 0 .

We would like also to emphasize, that $X_{\text {reach }}$ is a set of states reachable from the current state $x_{k}$ in general, without considering any particular conISSN 2663-2586 (Online), ISSN 2663-2578 (Print). Cyb. and comp. eng. 2020. № 1 (199) 
trol synthesis algorithm. So, it is a superset of the set of states, reachable with controls generated by the variational method. As a result, this method also gives us intermediate aims not further, than ones generated by the projection approach of the variational method. So, using $x^{\#}$ computed this way as the next intermediate aim also satisfies the theorem 4 .

But in practice we can't calculate the solution of the problem (15), (2) for any small $\alpha$ because of limited precision of computations with floating-point numbers. So, the best we can do is to stop decreasing $\alpha$ when next resulting control $u(k, s)$ leads the system into a state further from 0 than the one from previous result. This way we synthesize new sequence of controls with reasonable precision.

As a tradeoff between computation precision and speed, we also can choose a reasonably small $\alpha$ beforehand and solve the problem (15), (2) only with this value. Under uncertainty when $x_{k}$ is known with errors it is fully acceptable.

\section{Indexes Partitioning Method}

This approach was proposed and considered for the first time in [8].

The main idea of this approach is as follows. Firstly we try guess a right partition of index set $\overline{1 \ldots s r}$ into three subsets $I_{0}, I_{\min }$ and $I_{\max }$. Then we are trying to calculate a control $u(k, s)$ according to formulas:

$$
\begin{gathered}
u_{i}(k, s)=-u_{\max i}, \quad i \in I_{\min }, \\
u_{i}(k, s)=u_{\max i}, \quad i \in I_{\max }, \\
w_{I_{\min } \cup I_{\max }}=\left(\left(\Omega^{-1}\right)_{I_{\min } \cup I_{\max } \cup I_{\max }}\right)-1 \cdot\left(u_{I_{\min } \cup I_{\max }}(k, s)-\left(\Omega^{-1}\right)_{I_{\min } \cup I_{\max }} \cdot x^{* *}\right), \\
u_{I_{0}}(k, s)=\left(\Omega^{-1}\right)_{I_{0}} \cdot x^{* *}+\left(\Omega^{-1}\right)_{I_{0}}^{I_{\min } \cup I_{\max }} \cdot w_{I_{\min } \cup I_{\max }},
\end{gathered}
$$

where $\Omega=\Omega_{s}^{T} \Omega_{s}+\alpha E$ and $x^{* *}=\Omega_{s}^{T}\left(x^{*}-A^{s} x_{k}\right)$.

If resulting control satisfies constraints (2) and $w_{I_{\min }}>0, w_{I_{\max }}<0$ (strictness of this inequalities is significant), then we have found a solution of the problem (15) with constraints (2). In other case we should try another index set partition.

It would be great to have some kind of rule to choose next index set partition based on previous tried ones, so that it will lead us to the right one faster, than just trying all variants in sequence or randomly choosing next variant.

Sequential traversal rule. In [8, Sect. 6] was proposed such a rule, but with a caveat: for some particular problems it will lead the search of partition into loop. So, if we want to implement it in practice, we will need to also implement check for such loops. If a search loop was detected, we should choose next index set partition in some other way - for example, randomly.

We also need to decide on partition to check first. We suggest it to be $I_{0}=\overline{1 \ldots s r}, I_{\min }=\varnothing, I_{\max }=\varnothing$, because if $A^{s} x_{k}$ is in certain neighbour- 
hood of $x^{*}$, then the solution will correspond to this partition.

The idea of the sequential traversal rule is to decide next checked partition using calculations, which have been done for the previous partition. In particular, the next partition is generated as following:

- move from $I_{0}$ to $I_{\min }$ those $i \in I_{0}$, for which $u_{i}(k, s)<-u_{\max i}$ (this way it violates the constraint (2));

- move from $I_{0}$ to $I_{\max }$ those $i \in I_{0}$, for which $u_{i}(k, s)>u_{\max i}$ (this way it violates the constraint (2) as well);

- move from $I_{\min }$ to $I_{0}$ those $i \in I_{\min }$, for which $w_{i} \leq 0$;

- move from $I_{\max }$ to $I_{0}$ those $i \in I_{\max }$, for which $w_{i} \geq 0$.

This algorithm has one important property: if we try to produce with it next partition from a partition which corresponds to solution, we will get the same partition.

As it was already said, this algorithm can produce loops. So, if we build a directed graph of partition traversal, it will consist of one or more connected components. One of them, obviously, will contain the solution, and we will reach the solution if we start from any of nodes from this component. Search started from any node from other component will lead into loop.

According to results of our test runs with randomly generated problems, the situation when the search process falls into a loop is relatively rare. But it is not too rare to ignore this possibility. The results of this test runs are shown in Table 1.

In this table columns contain following:

- $n$ - dimensions of state;

- $\quad r$ - dimensions of control vector;

- $s$ - number of produced control's iterations;

- Trivial - number of samples with solutions corresponding to partition $I_{0}=\overline{1 \ldots s r}, \quad I_{\min }=\varnothing, I_{\max }=\varnothing$;

- Nontrivial - Number of samples, for which the solution was found without falling into a loop, excluding "Trivial" cases;

- First try - number of samples, for which the solution was found without falling into a loop ("Trivial" and "Nontrivial" cases);

- Loop - number of samples, for which search process have fallen into a loop;

- All - number of all problems with this $n, r$ and $s$ values tested.

We should empathise that distributions used in random sampling of problems are not chosen with some kind of reasonable methodology - it is only used here for illustrative purposes. The right way to do it is a topic for further discussion.

Table 1. Distribution of search situations for randomly generated problems for sequential traversal algorithm

\begin{tabular}{|c|c|c|c|c|c|c|c|}
\hline$n$ & $r$ & $s$ & Trivial & Nontrivial & First try & Loop & All \\
\hline 3 & 3 & 1 & 2117 & 7847 & 9964 & 36 & 10000 \\
4 & 3 & 2 & 6519 & 3059 & 9578 & 422 & 10000 \\
5 & 3 & 2 & 4646 & 4989 & 9635 & 365 & 10000 \\
6 & 3 & 2 & 2676 & 7243 & 9919 & 81 & 10000 \\
7 & 3 & 3 & 6125 & 3411 & 9536 & 464 & 10000 \\
\hline
\end{tabular}




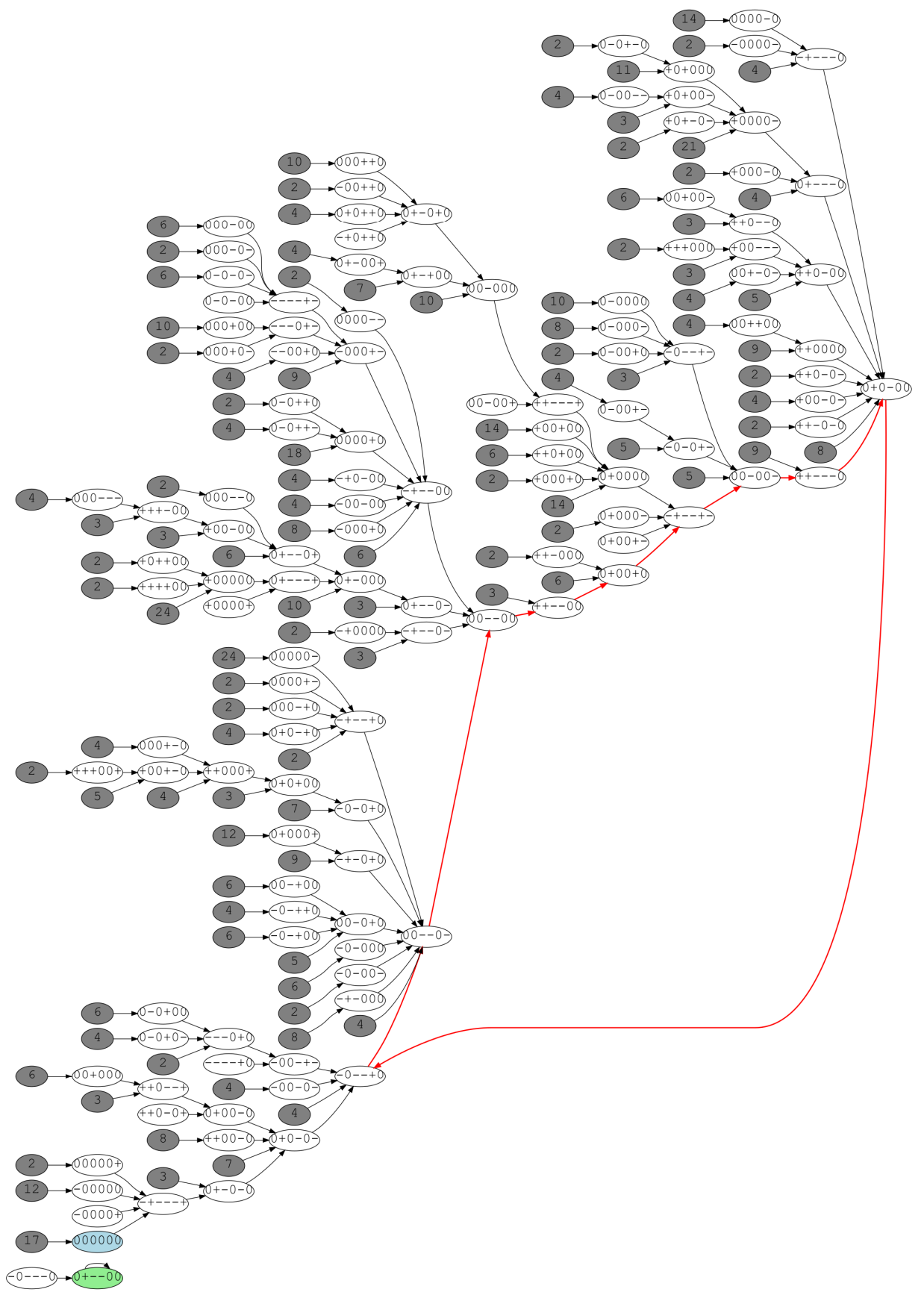

Fig. 1. A partition traversal graph with solution's component consisting of only two partitions 
In those unfortunate cases, when the partition traversal graph consists of several components, the number of partitions we would check before finding the right one highly depends on size of the component containing the searched partition. It is due to the fact, that if we detected a loop, we need to choose next partition randomly, and probability of continuing search from within the right graph's component is equal to the size of this component divided by the size of a partition pool we are choosing from. An extreme example of a search graph with a solutions' component consisting of only two nodes is shown on Figure 1.

On this figure we represent partitions as a strings consisting of symbols 0 , - and + , where each next symbol indicates, that corresponding index belongs to $I_{0}, I_{\min }$ or $I_{\max }$ respectively. The solutions' partition is marked with lightgreen colour. It can be also identified by a self-loop on it. The trivial partition $\left(I_{0}=\overline{1 . . s r}, I_{\min }=\varnothing, I_{\max }=\varnothing\right)$ is marked with light blue. The traversal loop is marked with red colour. Multiple source nodes of traversal graph which leads into the same next node is grouped in gray-coloured vertices labeled with number of the grouped nodes.

Fortunately, in most cases the traversal graph consists of only one component. Obviously, in this case the problem solution's partition can be either trivial or nontrivial. On the other hand, we have also found some rare cases with three components.

Fortunately, in most cases the traversal graph consists of only one component. Obviously, in this case the problem solution's partition can be either trivial or nontrivial. We have also found cases with two or three components.

As an alternative to loop detection we can instead detect repeated visits of the same graph nodes. It will guaranty, that the solution will be found in finite time. It will also make the search faster. But it requires considerable amount of memory.

\section{FEEDBACK STABILIZATION}

If we have a controllable system, for which full state vector is either measurable (i.e. the system is measurable) or can be estimated, then we can construct a feedback loop to control its state. The approach of the control theory is to apply some kind of linear transformation to the measured (or estimated) system's state. Contrary to it, we propose to use one of the control synthesis algorithms described above in the feedback loop to transform the current measured (or estimated) state into the control vector. But here arises a contradiction: at each point of time we need to generate only one control vector, while this method generates a whole sequence of them. There can be different approaches how to cope with it.

\section{Application schemes}

As it was already said, to take noises' impact into account, we need to recalculate controls anew after each control iteration. Otherwise, at the point of time $k+s$ deviation from expected trajectory will accumulate. In case of unstable or metastable system $(\|A\| \geq 1)$ the deviation can (and in most cases will) reach considerably large values. 
Thus next questions arise: for what horizon synthesize controls next time and what aim state $x^{*}$ to choose. The most evident application mode on fixed horizon is following:

1. at the point of time $k$ calculate controls for points of time from $k$ to $k+s-1$ inclusive and apply the first control from the calculated sequence. The expected state at the $k+s$ point of time denote as $x^{\#}$;

2. at each $k+i$ point of time, where $i \in \overline{1 \ldots s-1}$, calculate such control for horizon $k+i-k+s-1$, so that deviation between new expected state at $k+s$ point of time and $x^{\#}$ is minimal. Apply the first control from the newly generated control sequence. If $i=s-1$, then $k:=k+s$ and go to the first point.

This way we are striving to reach an intermediate aim $x^{\#}$ chosen at the point of time $k$. Let's call this scheme as a "strict with intermediate aim striving".

But it is not the most rational strategy. All theorems about attainability conditions proven here have one significant common point: the next intermediate aim's norm $\left\|x^{\#}\right\|$ must not be bigger than certain constraint. That's why we don't need to keep the same intermediate aim - it is enough to minimize the norm of the system's state at the $k+s$ point of time $\left\|x_{k+s}\right\|$. This approach is more rational, because in some cases noises may help us instead of interfering, and after their impact $x^{\#}$ may appear not to be the most close to 0 reachable state. Let's call this scheme as a "strict with striving for minimum".

There is also an experimental scheme, according to which we also recalculate the control sequence after each iteration, but we don't change the horizon length. Let's call this scheme as an "asymptotic". This scheme is not substantiated by the theorems proven in this article, but according to computational experiments it is also working.

If state measurement precision is proportionate to the trajectory deviation, it is appropriate to continue using previously generated control sequence.

\section{Algorithm testing}

Test were performed on a model cognitive map system, which can be described with equations

$$
\begin{gathered}
\Delta x_{k+1}=A \Delta x_{k}+B u_{k}+d_{k} \\
\Delta x_{k}=x_{k}-x_{k-1},
\end{gathered}
$$

where $x_{k}$ is a state of the system, $u_{k}$ is a control and, $d_{k}$ is the random perturbation at the moment $k ; A$ and $B$ are system matrices. 
The particular values used for the model system are as follow:

$$
\begin{gathered}
A=\left(\begin{array}{ccccccc}
0 & 1 & 0 & 0 & 0 & 0 & 0 \\
0 & 0 & 1 & 0 & 0 & 0 & 0 \\
0 & 0 & 0 & 1 & 0 & 0 & 0 \\
0 & 0 & 0 & 0 & 1 & 0 & 0 \\
0 & 0 & 0 & 0 & 0 & 1 & 0 \\
0 & 0 & 0 & 0 & 0 & 0 & 1 \\
-0,025 \ldots & 0,083 \ldots & -0,449 \ldots & 0,706 \ldots & -1,305 \ldots & 0,636 \ldots & 0,59
\end{array}\right) \\
B=\left(\begin{array}{cccc}
-0,88 & 0,73 & -0,84 \\
-0,39 & 0,44 & -0,56 \\
0,2 & 0,69 & -0,16 \\
-0,48 & 0,24 & -0,8 \\
-0,38 & 0,78 & 0,8 \\
0 & -0,46 & 0,09 \\
0,25 & -0,87 & 0,74
\end{array}\right)
\end{gathered}
$$

and uniformly distributed noise with interval $[-0,01 ; 0,01]$. Here matrix $A$ is a transposed frobenius matrix with eigenvalues $-1,27 ; 0,77 \pm 0,53 i ; 0,08 \pm 0,48 i$; $0,08 \pm 0,3 i$. Thus $A$ is an unstable matrix. The control synthesis were performed for horizons with length up to $s=6$ iterations.

The results of modelling for control schemes described in subsection 6.1 with the optimal aim control synthesis algorithm are depicted on Figures 2, 3 and 4. The results of modelling with applying whole generated control sequence without changes (in other words, without feedback) are depicted on Figure 5.

On these figures real system's trajectory is shown as blue line and forecasted trajectories are shown with different shades from black to light-gray. Forecasts for 6 steps ahead are shown with black; the most pale shade of gray depicts one-step forecasts. For each scheme there are two representations: for $x$ (actual system's state) and $\Delta x$ (impulse values). Because figures for different vector's components are similar, here we show only one typical component for short.

On Figures 2 and 3 we can see that initial convergence for the strict schemes is faster than initial convergence for the asymptotic scheme, as shown on Figure 4. On the other hand, the asymptotic scheme gives us less drifting of the system's state $x$ after initial stabilization phase in comparison with the strict schemes. And on Figure 5 we can see the consequences of applying whole generated control sequence to system without changes: the difference between forecasted and actual future state is rather big (except a few rather lucky occasions). The only reason why applying unchanged control sequence can still stabilize the system is because the noise's interval in this particular case is rather small. 
a)

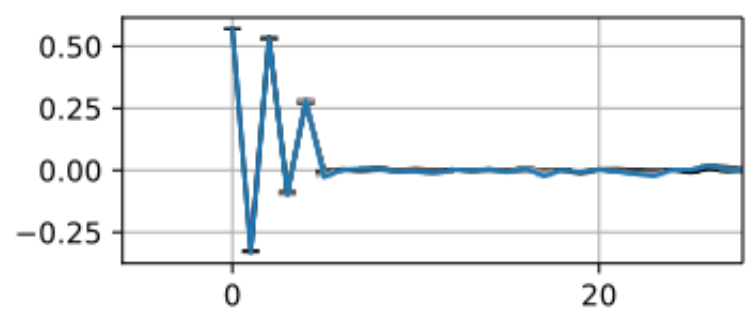

b)

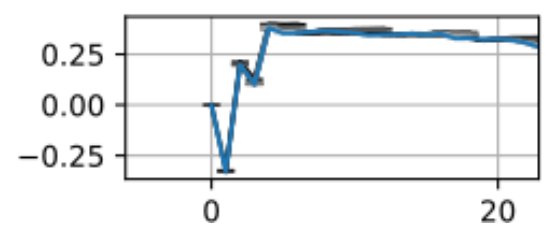

Fig. 2. Strict scheme with intermediate aim striving: a) for $\Delta x$, b) for $x$

a)

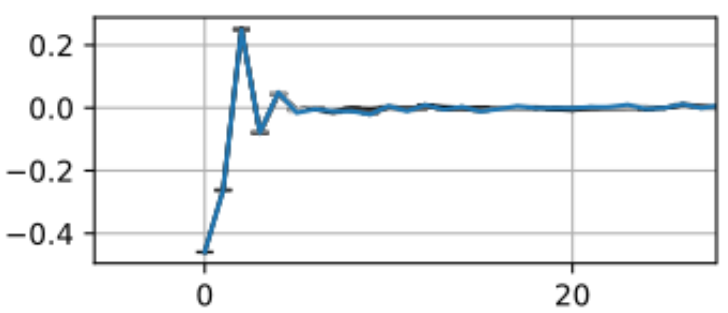

b)

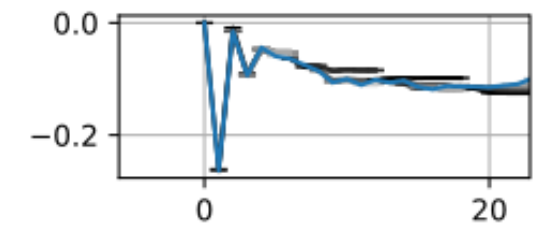

Fig. 3. Strict scheme with striving for minimum: a) for $\Delta x$, b) for $x$

a)

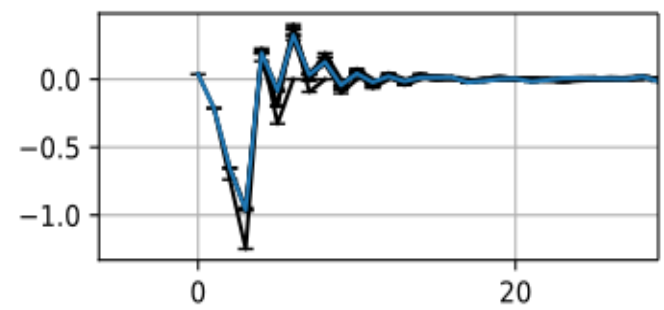

b)

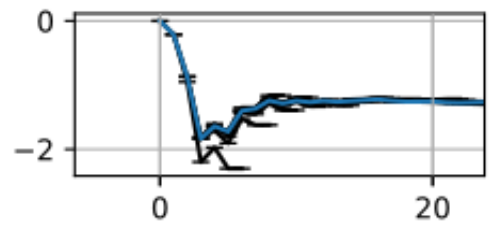

Fig. 4. Asymptotic scheme: a) for $\Delta x$, b) for $x$ 
a)

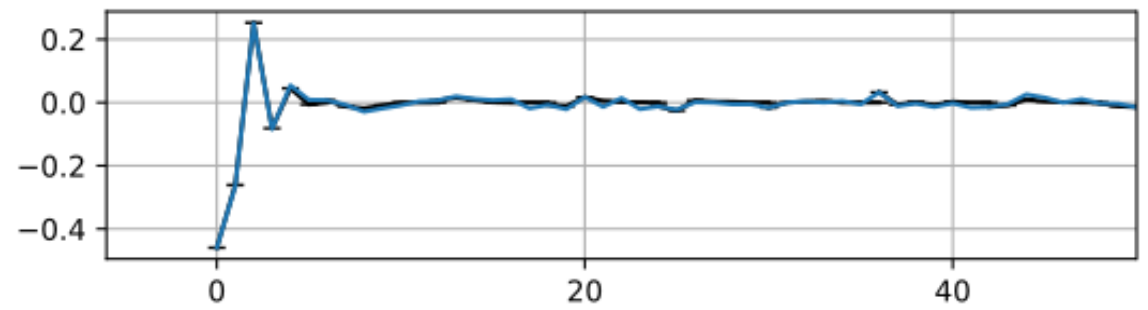

b)

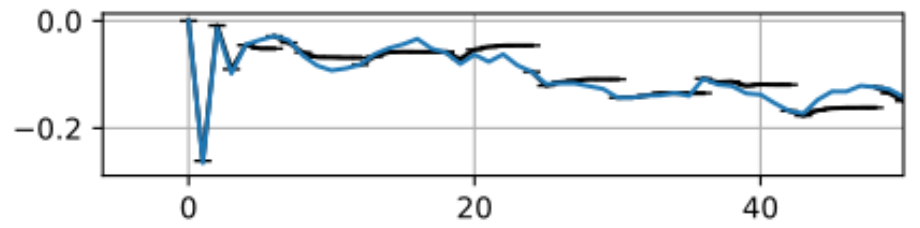

Fig. 5. Control without feedback a) for $\Delta x$, b) for $x$

\section{Combining application schemes}

The strict and asymptotic schemes have different qualities. The strict scheme is the most suitable for situations, when the last forecasted trajectory leads the system into 0 , while the asymptotic scheme is good either when the system's initial state is already in certain neighborhood of 0 (which size is proportional to the noise's standard deviation) or as a fallback for situations, when we can't lead the system's deterministic model to zero during predefined horizon $s$.

As a result, we propose to dynamically change the applied scheme as following. Suppose we have a system with $\mathrm{n}$-dimensional state vector $x$ and m-dimensional control vector $u$, we have chosen maximum horizon $s$ and we consider $\varepsilon$ neighborhood of 0 . Let $p$ be the smallest integer, for which $m \cdot p \geq n$. Then:

1. If the current system's state is out of the $\varepsilon$-neighborhood of 0 , synthesize a control sequence for horizon $s$.

1.1. If this sequence leads the deterministic system's model to 0 , then proceed with strict scheme by decreasing horizon length by one on each iteration. When the next horizon length according to the strict scheme should be less then $p$, decide again, what scheme to use. Also, if the system's state appear inside of the $\varepsilon$-neighborhood of 0 , go to the second clause.

1.2. If this sequence does not lead the deterministic system's model to 0 , then apply the first control of the generated sequence and decide again, what scheme to use. This way we will apply the asymptotic scheme until we can lead the deterministic system's model to 0 in $s$ iterations.

2. If the current system's state is inside of the $\varepsilon$-neighborhood of 0 , then synthesize a control sequence for horizon $p$. Apply the first control of the generated sequence and decide again, what scheme to use. This way we will apply the asymptotic scheme until the system's state will appear out of the $\varepsilon$ neighborhood of 0 for some unknown external reason. 


\section{CONCIUSIONS}

Original theoretical results developed in the paper are first of all oriented on practical application of different control strategies based on MPC for discrete linear MIMV system and derived from the obtained methods. The concept of finite horizon enables coordination of predictive interval and bounded uncertainty in suitable way. Under uncertainty instead of prescribed terminal point system will reach its vicinity so-called invariant set. With proposed approach there is no need to use conventional concept of stability according to Lyapunov.

MPC may also be used in case when instead of a full state vector measurement we have an incomplete measurement that is a vector with dimension less than $n$. In that case control system should include a state observer.

For MPC in case of noisy measurements we can use a state estimator based on data on back moving interval like those described in [9].

One of perspective applications of proposed methods is control of processes in cognitive maps.

\section{REFERENCES}

1. Garcia C. E., Prett D.M., Morari M. Model predictive control: Theory and Practice - a survey. Automatica. 1989 , no. 25 , pp. 335-347.

2. Rawlings, J. B., Muske K.R. The stability of constrained receding horizon control. IEEE Trans. Automat. Control. 1993, AC-38(10), pp. 1512-1516.

3. Mayne D. Q. Optimization in model based control. In Proc. IFAC Symposium Dynamics and Control of Chemical Reactors, Distillation Columns and Batch Processes. Helsingor. 1995. pp. 229-242.

4. Den Boom V. T. J. J. Model based predictive control: Status and perspective. In Symposium on Control, Optimization and Supervision, CESA'96 IMACS Multiconference. Lille, 1996. pp. 1-12.

5. Rawlings J.B., Mayne D.Q. Model Predictive Control: Theory and Design. Nob Hill Publishing, Madison, WI, 2009, ISBN 978-0-9759377-0-9. 576 p.

6. Richalet, J., Rault A., Testud J.L., Papon J. Model predictive heuristic control: Application to industrial processes. Automatica. 1978, no. 14, pp. 413-428.

7. Qin S.J., Badgwell T.A. An overview of industrial model predictive control technology. In Kantor Y.C., Garcia C.E. Carnahan (Eds) Chemical Process Control-Assessment and New Directions for Research AIChE Symposium series. V. 93, no. 316, pp. 232-256.

8. Gubarev V.F., Mishchenko M.D., Snizhko B.M. (Kondratenko Y., Chikrii A., Gubarev V., Kacprzyk J. (eds)). Model Predictive Control for Discrete MIMO Linear Systems. Advanced Control Techniques in Complex Engineering Systems: Theory and Applications. Studies in Systems, Decision and Control. 2019, Vol. 203.

9. Gubarev V.F., Shevchenko V.M., Zhykov A.O., Gummel A.V. State estimation for Systems Subjected to Bounded Uncertainty using Mooing Horizon Approach. In Preprints of the 15th IFAC Symposium on System Identification, Saint-Malo, France, 2009, pp. $910-915$.

Received 27.11.2019 
Міщенко М.Д. ${ }^{1}$, студент

e-mail: mishenkomihailo@gmail.com

Губарєв В.Ф. ${ }^{2}$, д-р. техн. наук, чл.-кор. НАН України,

зав. відд. керування динамічними системами

e-mail: v.f.gubarev@gmail.com

${ }^{1}$ Національний технічний університет України

«Київський політехнічний інститут імені Ігоря Сікорського»

пр. Перемоги, 37, м. Київ, 03056, Україна

${ }^{2}$ Інститут космічних досліджень НАН України та ДКА України, пр. Акад. Глушкова 40, корп. 4/1, 03187, Київ, Україна

\section{МЕТОДИ КЕРУВАННЯ ЗА ПРОГНОЗНОЮ МОДЕЛЛЮ ДЛЯ ДИСКРЕТНИХ СИСТЕМ 3 БАГАТЬМА ЗМІННИМИ ТА ВХОДАМИ}

Вступ. Значну кількість систем зручно моделювати як дискретну лінійну систему з багатьма входами та багатьма змінними. Коли постає задача керування такими системами, прийнято використовувати методи, розроблені на основі теорії керування. Проте ці методи мають низку відомих проблем. Наприклад, якщо розглядають недетерміновані системи, то виходять 3 припущення про певні статистичні властивості збурень.

Метою цієї статті було розроблення алгоритмів синтезу керування на основі ідей та підходів до керування за прогнозною моделлю.

Методи. На відміну від класичного підходу, у цій роботі за мету ставиться синтез найкращої за певним критерісм послідовності керування. Для синтезу застосовують результати, отримані за допомогою теореми Куна-Такера.

Результати. Отримано новий клас методів, здатних приводити стан лінійної системи до нуля (або у випадку наявності збурень - до його околу) та стабілізувати функціонування когнітивної карти за скінченний час. Отримані методи можуть керувати не тільки строго стійкими системами, а також і напівстійкими та нестійкими, зокрема і в умовах наявності випадкових збурень та з урахуванням обмеженості ресурсу керування.

Розроблені методи різняться за ефективністю використання ресурсу керування та необхідними обчислювальними ресурсами. Ефективніші методи потребують більше обчислень для отримання результату. Це призводить до необхідності вибирати оптимальний метод у кожному конкретному випадку окремо.

Висновки. Отримані методи можуть застосовуватися для керування як технічними, так і будь-якими іншими системами, які описуються як лінійні керовані системи 3 багатьма змінними та входами або як керовані когнітивні карти.

Розроблені методи залишають простір для подальших досліджень та покращень як самих обчислювальних алгоритмів, так і схем їхнього застосування.

Ключові слова: варіаційний метод, дискретна керована система, керування за прогнозною моделлю, когнітивна карта, лінійна система, синтез керування, ковзний інтервал. 
Мищенко М.Д. ${ }^{1}$, студент

e-mail: mishenkomihailo@gmail.com

Губарев В.Ф. ${ }^{2}$, д-р. техн. наук, чл.-корр. НАН Украины, зав. отд. управления динамическими системами

e-mail: v.f.gubarev@gmail.com

${ }^{1}$ Национальный технический университет Украины

«Киевский политехнический институт имени Игоря Сикорского»

пр. Победы, 37, г. Киев, 03056, Украина

${ }^{2}$ Институт космических иссделований НАН Украины и ГКА Украины, пр. Акад. Глушкова 40, 03187, Киев, Украина

\section{МЕТОДЫ УПРАВЛЕНИЯ ПО ПРОГНОЗИРУЮЩЕЙ МОДЕЛИ ДЛЯ ДИСКРЕТНЫХ СИСТЕМ СО МНОГИМИ ПЕРЕМЕННЫМИ И ВХОДОМ}

Введение. Существенное количество систем удобно моделировать как дискретную линейную систему со многими переменными. Когда ставится задача управления такими системами, принято использовать методы, построенные на основе теории управления. Однако эти методы имеют перечень известных проблем. Например, в случае, если рассматривается недетерминированная система, то такие методы исходят из предположения о некоторых статистических свойствах, возникающих в системе возмущений.

Цель статьи - разработка алгоритмов синтеза управления на основе прогнозирующей модели.

Методы. В отличие от классического подхода, в данном труде за цель ставится синтез наилучшей по определенному критерию последовательности управлений. Для синтеза используются результаты, полученные с помощью теоремы Куна-Такера.

Результаты. Был получен новый класс методов, способных приводить состояние линейной системы к нулю (или, в случае присутствия возмущений, к его окрестности) и стабилизировать функционирование когнитивных карт за конечное время. Полученные методы способны управлять не только строго устойчивыми системами, но и системами на грани устойчивости и неустойчивости, в том числе и в условиях присутствия случайных возмущений и с учетом ограниченности ресурса управления.

Разработанные методы различаются эффективностью использования ресурса управления и необходимыми вычислительными ресурсами. Более эффективные методы требуют большего количества вычислений для получения результата. Это приводит к необходимости в каждом конкретном случае выбирать свой наиболее оптимальный метод.

Выводы. Полученные методы могут применяться в управлении как техническими, так и любыми другими системами, которые описываются как линейные управляемые системы со многими переменными и входами или как когнитивные карты.

Разработанные методы оставляют пространство для дальнейших исследований и улучшений как самих вычислительных алгоритмов, так и схем их применения.

Ключевые слова: вариационный метод, дискретная управляемая система, управление по прогнозирующей модели, когнитивная карта, линейная система, синтез управления, скользящий интервал. 